\title{
Managing Auto Immune Hemolytic Anemia in Pregnancy with Thalassemia Trait
}

\author{
Keerti Angampally ${ }^{1 *}$, Dr. S Pandu Ranga Rao $^{2}$, Pooja Veturi ${ }^{3}$, Venkat $\mathrm{S}^{4}$
}

${ }^{1}$ 3rd year Post Graduate, Kamineni Institute of Medical College, Narketpalle, Telangana 508254, India

${ }^{2}$ Professor and Head of Department, Kamineni Institute of Medical College, Narketpalle, Telangana 508254, India

${ }^{3}$ 2nd year Post Graduate, Kamineni Institute of Medical College, Narketpalle, Telangana 508254, India

${ }^{4}$ Associate Professor, Kamineni Institute of Medical College, Narketpalle, Telangana 508254, India

DOI: $10.36347 /$ sjmcr.2020.v08i02.022

| Received: 10.02.2020 | Accepted: 17.02.2020 | Published: 21.02.2020

*Corresponding author: Dr. Keerti A

Abstract

Case Report

Nutritional anemia most common type of anemia presenting in women. Auto Immune Hemolytic Anemia (AIHA) is a relatively uncommon cause of anemia in pregnancy with a little literature available. Thalassemia trait do not experience any health problem except for mild anemia. At present we report a case of pregnant women with history of chronic anemia found to be Warm Auto Immune Hemolytic anemia with beta thalassemia trait.

Keywords: Pregnancy, anemia, warm auto immune hemolytic anemia, Thalassemia trait.

Copyright @ 2020: This is an open-access article distributed under the terms of the Creative Commons Attribution license which permits unrestricted use, distribution, and reproduction in any medium for non-commercial use (NonCommercial, or CC-BY-NC) provided the original author and source are credited.

\section{INTRODUCTION}

During pregnancy many women present with anemia. There are different kinds and different causes of anemia causing decreased red cells production. It can become serious problem and requires proper workup and management we here report a case of pregnant women with history of chronic anemia and previous pregnancy loss due to AIHA and $b$ thalassemia trait.

\section{CASE Report}

A 19 years old G3P1D1A1 with 22 weeks 5days of Gestation with Gestational Diabetes mellitus on medical nutritional therapy coming for regular antenatal checkup found to be anemia .On investigating her HAEMOGLOBIN was $6.5 \mathrm{gm} \%$, Total leucocyte count-13500, Platelet count -2.66 lakh/cumm. Peripheral smear showed mild anisopoikilocytosis, few microcytes, few tear drop cells, fragmented RBC, predominantly - microcytic hypochromic. Total bilirubin $-2.52 \mathrm{mg} / \mathrm{dl}$, Direct bilirubin $-0.56 \mathrm{mg} / \mathrm{dl}$

Differential diagnosis of microcytic hypochromic anemia are iron deficiency anemia, Thalassemia, Sideroblastic anemia [1].

\section{Sr. Iron -71, S. ferritin -132}

It was consanguineous marriage, along with history of spontaneous abortion in her first pregnancy and death of her one month baby with jaundice and in view of her chronic anemia, her blood sample was sent for $\mathrm{HB}$ electrophoresis to rule out any inherited defects of hemoglobin it turned out as thalassemia trait.

With previous history of transfusion and raised bilirubin levels, her blood sample was sent to department of transfusion medicine for evaluation of hemolytic anemia.

\begin{tabular}{|l|l|l|l|l|c|}
\hline DCT & IN HOUSE PANEL & \multicolumn{3}{|c|}{ ICT } & AC \\
\hline & & I & II & III & \\
\hline $3+$ & NEGATIVE & NEGATIVE & NEGATIVE & NEGATIVE & $3+$ \\
\hline \multicolumn{4}{|l}{ INTERPRETATION : AUTO IMMUNE HEMOLYTIC ANEMIA } \\
\hline
\end{tabular}

Thermal amplitude test was done to specify type of antibodies - warm or cold auto immune hemolytic anemia. Titers of 64 were seen at $37^{\circ} \mathrm{C}$, suggesting of warm Auto Immune Hemolytic Anemia.
This is a case Warm auto immune hemolytic anemia in pregnant women with thalassemia trait. 


\section{DISCUSSION}

This case explores the importance of proper investigation and work up of anemia in pregnancy. Thalassemia is quantitative defects of globin chains. They are an important cause of morbidity and mortality worldwide. They create a huge emotional and financial deficit on the affected individuals and their families, society and the country [2]. Pregnancy in women with thalassemia trait appears to have no adverse effects on progression of disease but are associated with high rate thrombotic events as well as high rate of intrauterine growth restriction [3]. Hence pregnant women presenting with anaemia should be screened for carriers of thalassemia and other hemoglobinopathies along with their husbands so as to identify the couples at risk of having severely affected children [4]. In this case ante natal screening of mother in first pregnancy would have resulted in better obstetric history.

Immune hemolytic anemia (IHA) is a condition in which antibodies of immunoglobulin $\mathrm{G}$ (IgG) and/or immunoglobulin $\mathrm{M}(\operatorname{IgM})$ bind to red cell surface antigens and initiate red cell destruction via the complement system and the reticulo-endothelial system. IHA is classified as either autoimmune, alloimmune or drug induced based on the antigenic stimulus responsible for the immune response [5]. AIHA occurs when antibodies are directed against persons own RBC s causing them to lyse leading to an insufficient number of oxygen -carrying red blood cells in circulation [5]. Genetic factors, infection, inflammatory disorders, drugs, lymphoproliferative disorders etc., often serve as the trigger to initiate the emergence of autoantibodies [6]. Our case mostly trigger might be previous transfusions.

Our patient responded well to steroids (Glucocorticoids are the first-line treatment for anemia due to warm AIHA) [4] and with compatible unit transfusions her hemoglobin raised to $10 \mathrm{~g} / \mathrm{dl}$ and is maintaining. Her bilirubin levels were also reduced over 2 week period.

Managing pregnant women with Thalassemia trait is Proper transfusion support in the form of best matched units and increase frequency of blood transfusion to maintain pre transfusion $\mathrm{HB}$ above $10 \mathrm{~g}$ /dl. Serial ultrasound scan to monitor fetal growth can help in better fetal outcomes. Investigation on father like HB electrophoresis, Counselling about fetal outcomes [3].

\section{Conclusion}

- Pregnant women presenting with anemia should be screened for carriers of thalassemia and other hemoglobinopathies along with their husbands so as to identify the couples at risk of having severely affected children.

- AIHA should be considered in cases of severe anemia during pregnancy. Warm AIHA in pregnancy is challenging especially transfusion support, the most compatible red blood cells (i.e., those with the least cross-reacting antibodies) should be given. The main purpose of the treatment of AIHA is to stop hemolysis and correct anemia. The nature of the AIHA is still not completely understood and needs further investigation.

\section{REFERENCES}

1. Meredith JL, Rosenthal NS. Differential diagnosis of microcytic anemias. Laboratory Medicine. 1999 Aug 1;30(8):538-42.

2. Shukla S, Singh D, Dewan K, Sharma S, Trivedi SS. Antenatal carrier screening for thalassemia and related hemoglobinopathies: A hospital-based study. Journal of Medical Society. 2018 May 1;32(2):118-22.

3. Cappellini MD, Cohen A, Porter J, Taher A, Viprakasit V, editors. Guidelines for the management of transfusion dependent thalassaemia (TDT). Nicosia, Cyprus: Thalassaemia International Federation; 2014.

4. Gorakshakar AC, Colah RB. Cascade screening for $\beta$-thalassemia: a practical approach for identifying and counseling carriers in India. Indian journal of community medicine: official publication of Indian Association of Preventive \& Social Medicine. 2009 Oct;34(4):354-356.

5. Gehrs BC, Friedberg RC. Autoimmune hemolytic anemia. American journal of hematology. 2002 Apr;69(4):258-71

6. Chaudhary RK, Das SS. Autoimmune hemolytic anemia: From lab to bedside. Asian journal of transfusion science. 2014 Jan;8(1):5-12. 